\title{
Glucose-Lowering Effect of Insulin Degludec is Independent of Subcutaneous Injection Region
}

\author{
Leszek Nosek • Hans-Veit Coester • Carsten Roepstorff • \\ Henrik F. Thomsen $\cdot$ Niels R. Kristensen • \\ Hanne Haahr $\cdot$ Tim Heise
}

Published online: 16 August 2014

(C) The Author(s) 2014. This article is published with open access at Springerlink.com

\begin{abstract}
Background and Objectives Patients with diabetes mellitus inject insulin in different regions of the body. This study investigated the pharmacokinetic and pharmacodynamic properties of insulin degludec (IDeg), a new-generation once-daily basal insulin with an ultra-long duration
\end{abstract}

These data were previously presented at congress: Nosek L, Coester H-V, Thomsen HF, Roepstorff C, Haahr HL, Heise T. Glucoselowering effect of insulin degludec is independent of subcutaneous injection region. Diabetes 2012 Jun;61:A212-344; doi:10.2337/db12-836-1328.

Electronic supplementary material The online version of this article (doi:10.1007/s40261-014-0218-x) contains supplementary material, which is available to authorized users.

L. Nosek $(\bowtie) \cdot$ H.-V. Coester · T. Heise

Profil Institut für Stoffwechselforschung $\mathrm{GmbH}$,

Hellersbergstraße 9, 41460 Neuss, Germany

e-mail: leszek.nosek@profil.com

C. Roepstorff · N. R. Kristensen · H. Haahr

Novo Nordisk A/S, Søborg, Denmark

H. F. Thomsen

Novo Nordisk A/S, Aalborg, Denmark of action, after subcutaneous (SC) administration in different injection regions.

Methods In this study, 20 healthy subjects received single SC doses of IDeg ( $0.4 \mathrm{U} / \mathrm{kg}$; separated by 13-21 days) in the thigh, abdomen and deltoid in a randomised, openlabel, single-centre, single-dose, complete crossover trial. Each dose was followed by a 24-h euglycaemic clamp and 120-h pharmacokinetic blood sampling. The obtained pharmacokinetic/pharmacodynamic profiles were extrapolated to steady state by simulation using a pharmacokinetic/ pharmacodynamic model.

Results Total IDeg exposure [area under the IDeg serum concentration-time curve $0-120 \mathrm{~h}$ after a single dose $\left.\left(\mathrm{AUC}_{\mathrm{IDeg}, 0-120 \mathrm{~h}, \mathrm{SD}}\right)\right]$ and maximum serum concentration [maximum IDeg serum concentration after a single dose $\left.\left(C_{\text {max,IDeg,SD }}\right)\right]$ were higher $(6-7$ and $23-27 \%$, respectively) following a single SC dose in the deltoid or abdomen, compared with the thigh, as also observed with other insulin preparations. No statistical difference was observed in these measures between deltoid and abdominal administration. No pronounced differences were observed in the glucose-lowering effect of IDeg [area under the glucose infusion rate (GIR) curve $0-24 \mathrm{~h}$ after a single dose $\left(\mathrm{AUC}_{\mathrm{GIR}, 0-24 \mathrm{~h}, \mathrm{SD}}\right)$ and maximum GIR after a single dose $\left.\left(\mathrm{GIR}_{\max , \mathrm{SD}}\right)\right]$ when injected in the thigh, abdomen or deltoid $\left(\mathrm{AUC}_{\mathrm{GIR}, 0-24 \mathrm{~h}, \mathrm{SD}} 2,572,2,833\right.$ and $2,960 \mathrm{mg} / \mathrm{kg}$, respectively). Simulated mean steady-state pharmacokinetic and pharmacodynamic profiles supported a flat and stable IDeg exposure and effect regardless of injection region, with comparable total glucose-lowering effects [area under the GIR curve at steady state $\left(\mathrm{AUC}_{\mathrm{GIR}, \tau, \mathrm{SS}}\right)$ ] between the thigh, abdomen and deltoid.

Conclusions These findings support administering IDeg SC in the thigh, upper arm or abdominal wall without affecting IDeg absorption or effect at steady state. 


\section{Key Points}

Insulin degludec (IDeg) has an ultra-long duration of action that is mediated by the formation of stable multi-hexamers in the subcutaneous (SC) tissue upon injection, resulting in a soluble depot from which IDeg monomers are slowly released into the circulation.

This study found that IDeg has a flat and stable glucose-lowering effect which is independent of injection region (thigh, abdomen, deltoid).

These results support administering IDeg SC in the thigh, upper arm or abdominal wall without affecting IDeg absorption or effect at steady state.

\section{Introduction}

Diabetes mellitus patients inject insulin in different regions of the body according to personal preference and activity pattern [1-3]. However, differences can exist in the pharmacokinetic and pharmacodynamic properties of insulin following subcutaneous (SC) administration in different regions [4-10].

Insulin degludec (IDeg), a new-generation basal insulin with an ultra-long duration of action, developed for oncedaily administration, has a distinct mechanism of protraction [11]. In contrast to other basal insulin preparations, which form crystals or precipitate upon SC injection [1215], IDeg stays in solution and forms stable multi-hexamers in the SC tissue from which IDeg monomers gradually separate, producing a slow absorption into the circulation with low day-to-day variability [11, 16, 17]. IDeg has a considerably longer half-life after SC administration than insulin glargine (25 vs. $12 \mathrm{~h})$ [18] and exhibits a duration of action longer than $42 \mathrm{~h}[11,16]$. The soluble multi-hexamer formation, slow absorption and ultra-long duration of action of IDeg raise the possibility that any differences in pharmacokinetic and pharmacodynamic properties seen between injection regions after a single dose of IDeg may diminish at steady state.

In this single-dose study, we investigated the pharmacokinetic and pharmacodynamic properties of IDeg after SC dosing in the thigh, abdomen or deltoid (upper arm). In addition, a pharmacokinetic/pharmacodynamic model was developed based on the obtained data to simulate the pharmacokinetic and pharmacodynamic profiles of IDeg at steady state for each injection region.

\section{Materials and Methods}

\subsection{Study Design}

This randomised, open-label, five-period, single-centre (Profil, Germany), single-dose crossover trial was conducted in healthy subjects (ClinicalTrials.gov identifier: NCT01151072). The study protocol was reviewed and approved by the health authority (Bundesinstitut für Arzneimittel und Medizinprodukte) according to local regulations and by the ethics committee of Ärztekammer Nordrhein. The study was performed in accordance with the Declaration of Helsinki and its amendments, and in accordance with Good Clinical Practice as defined by the International Conference on Harmonisation. Subjects were informed of the risks and benefits of the trial and were informed that they could withdraw at any time for any reason. Consent was obtained in writing before any trialrelated activities, and the investigator retained the consent forms.

\subsection{Subjects}

Study subjects were healthy males or females aged 18-55 years, with a body mass index (BMI) of $18.0-27.0 \mathrm{~kg} / \mathrm{m}^{2}$ and fasting plasma glucose concentrations of $\leq 6.0 \mathrm{mmol} / \mathrm{L}(\leq 108 \mathrm{mg} / \mathrm{dL})$. Key exclusion criteria for participation in the study included the use of prescription drugs within 3 weeks prior to screening, the use of non-prescription drugs (including over-the-counter medication, non-routine vitamins and herbal products) within 3 weeks prior to screening, and smoking.

\subsection{Interventions and Pharmacokinetic Sampling}

Following screening (Visit 1), subjects were randomised to predetermined dosing sequences consisting of five single doses of IDeg on five separate dosing visits (Visits 2-6). Dosing was conducted via SC injection of $0.4 \mathrm{U} / \mathrm{kg}$ body weight (BW) of IDeg in the thigh, abdomen or deltoid (upper arm); intramuscular (IM) injection of $0.4 \mathrm{U} / \mathrm{kg} \mathrm{BW}$ of IDeg in the thigh area; or intravenous (IV) injection of $0.04 \mathrm{U} / \mathrm{kg}$ BW of IDeg. Only the methods and data from the SC dosing arms are reported here. IDeg was provided in $3 \mathrm{~mL}$ Penfill ${ }^{\circledR}$ cartridges $(100 \mathrm{U} / \mathrm{mL}$ ) (Novo Nordisk A/S, Bagsværd, Denmark) for dosing and administered (using a syringe and needle) into a lifted skinfold in either the anterior surface of the thigh, the lower abdominal wall (above the inguinal area) or the outer aspect of the deltoid area.

At each dosing visit, IDeg administration was followed by a 24-h euglycaemic clamp procedure (see below for description). Subjects attended dosing visits in a fasted 
state, and each subject remained in the clinic for $48 \mathrm{~h}$ after dosing, during which blood samples for pharmacokinetic analysis were taken frequently. Blood samples were also taken frequently for analysis of blood glucose concentrations. Subjects subsequently returned to the clinic at 24-h intervals. Blood samples were taken at these visits (at 72 , 96 and $120 \mathrm{~h}$ post-dosing) for pharmacokinetic assessment. Dosing visits were separated by a washout period of 13-21 days. An interval of 7-21 days existed between the last of the five dosing visits and a subsequent follow-up visit (Visit 7).

\subsection{Euglycaemic Clamp Procedure}

Subjects remained fasted (with water ad libitum) and in a supine position for the euglycaemic clamp procedure (Biostator $^{\circledR}$, MTB Medizintechnik, Amstetten, Germany); target blood glucose: $4.5 \mathrm{mmol} / \mathrm{L}(81 \mathrm{mg} / \mathrm{dL})$. One to 6 hours before dosing, subjects received a variable IV infusion of human insulin [15 (I)U Actrapid ${ }^{\circledR}$ (Novo Nordisk A/S, Bagsværd, Denmark), 100 (I)U/mL in $49 \mathrm{~mL}$ saline and $1 \mathrm{~mL}$ of subject's blood] or glucose $(20 \%)$ to obtain the glucose clamp target concentration. The target glucose concentration was maintained for at least $1 \mathrm{~h}$ before dosing, without any glucose infusion. After dosing, the rate of insulin infusion, if any, was decreased gradually and terminated when glucose concentrations had declined by approximately $0.3 \mathrm{mmol} / \mathrm{L}(5 \mathrm{mg} / \mathrm{dL})$. A variable IV glucose infusion was then initiated to maintain the clamp target concentration.

\subsection{Data and Statistical Analyses}

The primary objective of this study was to investigate the relative exposure among different SC administration regions in healthy subjects following single-dose administration. Secondary objectives were evaluation of the pharmacokinetic and pharmacodynamic profiles and the safety and tolerability of IDeg.

Serum concentrations of IDeg were measured using an IDeg-specific sandwich ELISA, with a lower limit of quantification of $20 \mathrm{pmol} / \mathrm{L}$. The primary endpoint was the area under the IDeg serum concentration-time curve 0-120 h after a single dose (AUC IDeg,0-120h,SD given by $\mathrm{SC}$ administration in the thigh, abdomen or deltoid area. AUC $_{\text {IDeg,0-120h,SD }}$ was derived by non-compartmental analysis using the linear trapezoidal technique based on observed values and actual measurement times between 0 and $120 \mathrm{~h}$, with missing values interpolated. The logtransformed $\mathrm{AUC}_{\mathrm{IDeg}, 0-120 \mathrm{~h}, \mathrm{SD}}$ was analysed using an ANOVA method with injection region and treatment period as fixed factors and subject as a random effect. In order to account for potential heteroscedasticity, the error-term was dependent on the injection region. The maximum IDeg serum concentration after a single dose $\left(C_{\text {max,IDeg,SD }}\right)$ was also assessed. $C_{\text {max,IDeg,SD }}$ was derived from individual concentration-time curves and analysed using the same approach as for $\mathrm{AUC}_{\mathrm{IDeg}, 0-120 \mathrm{~h}, \mathrm{SD}}$.

Pharmacodynamic endpoints included the area under the glucose infusion rate (GIR) curve $0-24 \mathrm{~h}$ after a single dose $\left(\mathrm{AUC}_{\mathrm{GIR}, 0-24 \mathrm{~h}, \mathrm{SD}}\right)$ and maximum GIR after a single dose $\left(\mathrm{GIR}_{\max , \mathrm{SD}}\right)$. GIR data were smoothed using the Loess smoothing technique (fixed smoothing parameter of 0.25). Pharmacodynamic endpoints were summarised using descriptive statistics.

To predict the steady-state pharmacokinetic and pharmacodynamic profiles of IDeg following SC administration, a pharmacokinetic/pharmacodynamic model using single-dose IDeg data from the current study was applied, with area under the concentrationtime curve (AUC) derived by non-compartmental analysis. The pharmacokinetic component of the model consisted of an absorption part with a depot compartment, a transit compartment, a bioavailability parameter, an absorption rate parameter and a transit rate parameter; and a disposition part with two compartments, two clearance parameters and two volume of distribution parameters. The pharmacodynamic component of the model linked the IDeg concentration to GIR by means of an effect compartment, a turnover parameter, an insulin sensitivity parameter and an underlying GIR baseline parameter. The parameters of the model were estimated in a population pharmacokinetic/pharmacodynamic setting, using a non-linear mixed-effects approach, which allowed individual sets of the ten parameters for each of the subjects included in the trial to be obtained. The bioavailability parameter and the absorption rate parameter were allowed to vary between injection regions for each subject. The values of the absorption rate parameter were subsequently calibrated based on information from the comprehensive clinical pharmacology programme of studies conducted with IDeg. The same calibration factor was applied for all subjects and all injection regions. Using the estimated individual parameters, a simulation of once-daily multiple dosing was conducted to obtain mean steady-state profiles. More specifically, once-daily multiple dosing for 6 days at a dose level of $0.4 \mathrm{U} / \mathrm{kg}$ was simulated by extrapolating the profile for each of the subjects, and for each injection region, and subsequently calculating the mean of the profiles on Day 6.

Safety endpoints, including adverse events (AEs), laboratory safety variables, physical examination, vital signs, ECG, hypoglycaemic episodes and local tolerability at injection site, were monitored and summarised using descriptive statistics. 


\section{Results}

\subsection{Subjects}

Twenty-two subjects were screened; two subjects were screening failures (both had first-degree relatives with diabetes). Twenty subjects (17 males and three females) were randomised, and 19 subjects completed the trial. One subject withdrew from the trial for personal reasons after having completed the first three dosing visits (the subject did not complete SC and IM injection in the thigh). All 20 randomised subjects were included in the full analysis set and the safety analysis set.

The mean [standard deviation (SD)] age of subjects who were randomised to dosing sequences was 37.4 (9.5) years, the mean (SD) BW was 76.4 (12.0) $\mathrm{kg}$ and the mean (SD) BMI was $24.1(2.4) \mathrm{kg} / \mathrm{m}^{2}$. The majority of subjects (17/20) were caucasian, two were African American and one was Asian non-Indian.

\subsection{Single-Dose and Simulated Steady-State Pharmacokinetics}

Single-dose 24-h mean pharmacokinetic profiles are shown in Fig. 1a. Total exposure of IDeg $\left(\mathrm{AUC}_{\mathrm{I}-}\right.$ Deg,0-120h,SD) was 6-7\% higher following a single SC injection in the deltoid or abdomen than in the thigh (Table 1). No difference in $\mathrm{AUC}_{\mathrm{IDeg}, 0-120 \mathrm{~h}, \mathrm{SD}}$ was found between the deltoid and abdomen. The maximum concentration of IDeg $\left(C_{\text {max,IDeg,SD }}\right)$ was $23-27 \%$ higher following a single $\mathrm{SC}$ injection in the deltoid or abdomen than in the thigh (Table 1). No difference in $C_{\text {max,IDeg,SD }}$ was found between the deltoid and abdomen.

Simulated mean pharmacokinetic profiles at steady state showed an even distribution of IDeg exposure across a 24-h dosing interval regardless of injection region (Fig. 1b). Simulated steady-state exposure [area under the insulin degludec serum concentration-time curve at steady state $\left.\left(\mathrm{AUC}_{\mathrm{IDeg}, \tau, \mathrm{SS}}\right)\right]$ was predicted to be $\sim 8 \%$ higher following injection in the deltoid or abdomen than in the thigh (Table 1).

The observed differences in $C_{\text {max,IDeg,SD }}$ diminished at steady state; the maximum IDeg serum concentration at steady state $\left(C_{\text {max,IDeg,Ss }}\right)$ was estimated to be $10 \%$ higher following injection in the deltoid or abdomen than in the thigh (Table 1).

\subsection{Single-Dose and Simulated Steady-State Pharmacodynamics}

Single-dose 24-h mean pharmacodynamic profiles are shown in Fig. 2a. No pronounced differences in the
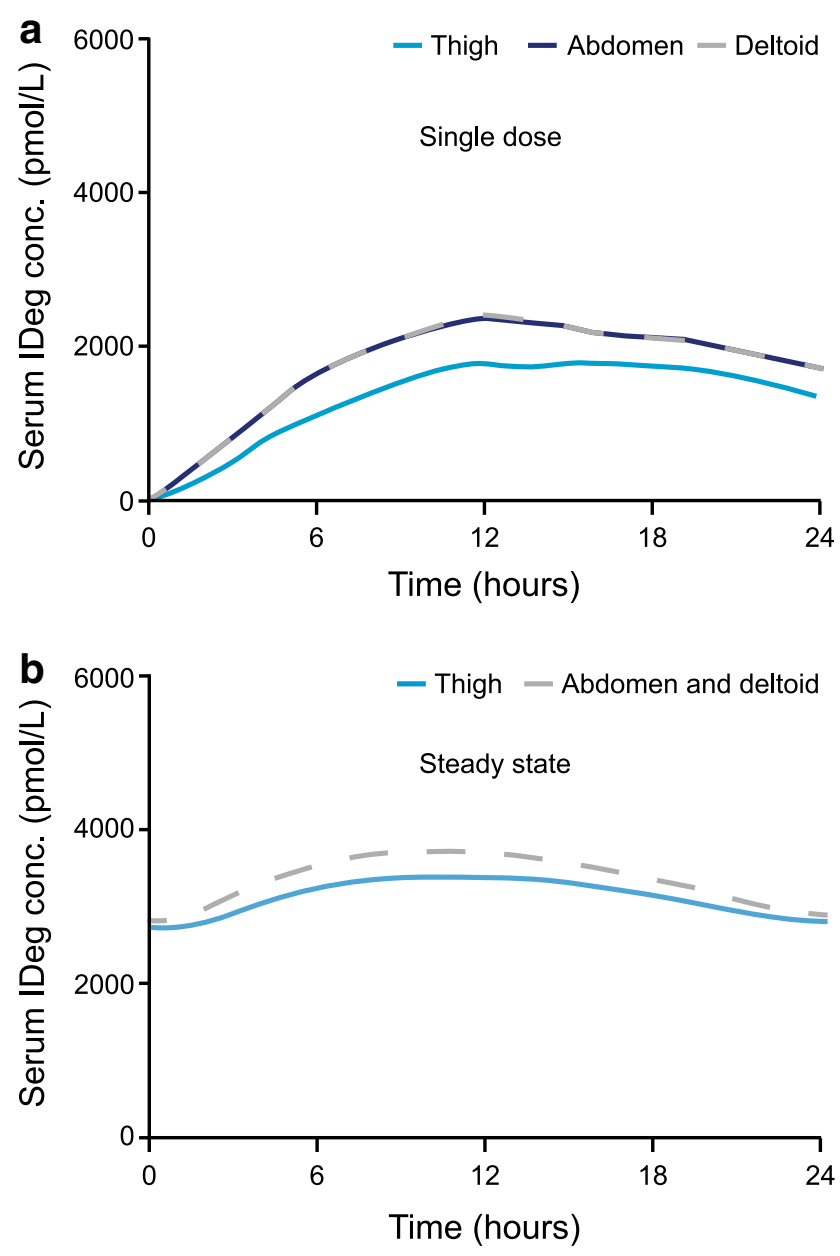

Fig. 1 a Mean 24-h pharmacokinetic profiles after a single subcutaneous dose of insulin degludec $(0.4 \mathrm{U} / \mathrm{kg})$, administered in the thigh, abdomen or deltoid. b Mean 24-h pharmacokinetic profiles when simulated to steady state after once-daily subcutaneous administration of insulin degludec $(0.4 \mathrm{U} / \mathrm{kg})$ in the thigh, abdomen or deltoid. Because there was no difference in total exposure $\left(\mathrm{AUC}_{\mathrm{IDeg}, 0-120 \mathrm{~h}, \mathrm{SD}}\right)$ between the deltoid and abdomen after a single dose, the pharmacokinetic profiles for these two injection regions are superimposed in the steady-state simulation. $A U C_{I D e g, 0-120 h, S D}$ area under the insulin degludec serum concentration-time curve $0-120 \mathrm{~h}$ after a single dose, conc. concentration, IDeg insulin degludec

glucose-lowering effect of IDeg $\left(\mathrm{AUC}_{\mathrm{GIR}, 0-24 \mathrm{~h}, \mathrm{SD}}\right.$ and $\mathrm{GIR}_{\max , \mathrm{SD}}$ ) were evident following a single $\mathrm{SC}$ injection in the thigh, abdomen or deltoid (Table 2). The glucoselowering effect extended beyond $24 \mathrm{~h}$ in all subjects for all three SC injection regions.

In accordance with the simulated steady-state pharmacokinetic profiles, the simulated mean steady-state pharmacodynamic profiles showed an even distribution of glucose-lowering effect across a 24-h dosing interval (Fig. 2b). The simulated glucose-lowering effect of IDeg at steady state did not show any relevant differences among the three SC injection regions (Table 2). 
Table 1 Pharmacokinetic endpoints of insulin degludec following a single subcutaneous injection in the thigh, abdomen or deltoid and simulation-based once-daily steady-state values

\begin{tabular}{|c|c|c|}
\hline Pharmacokinetic endpoint & $\begin{array}{l}\text { Mean } \\
\text { estimate }\end{array}$ & $\begin{array}{l}\text { Mean ratio } \\
{[95 \% \mathrm{CI}]}\end{array}$ \\
\hline \multicolumn{3}{|l|}{ Single dose } \\
\hline \multicolumn{3}{|l|}{$\mathrm{AUC}_{\mathrm{IDeg}, 0-120 \mathrm{~h}, \mathrm{SD}}(\mathrm{pmol} \cdot \mathrm{h} / \mathrm{L})$} \\
\hline Thigh & 76,679 & \\
\hline Abdomen & 82,059 & \\
\hline Deltoid & 81,135 & \\
\hline Deltoid vs. thigh & & $1.06[1.01-1.10]$ \\
\hline Abdomen vs. thigh & & $1.07[1.03-1.11]$ \\
\hline Abdomen vs. deltoid & & $1.01[0.96-1.06]$ \\
\hline \multicolumn{3}{|l|}{$C_{\text {max,IDeg,SD }}(\mathrm{pmol} / \mathrm{L})$} \\
\hline Thigh & 1,938 & \\
\hline Abdomen & 2,388 & \\
\hline Deltoid & 2,462 & \\
\hline Deltoid vs. thigh & & $1.27[1.08-1.49]$ \\
\hline Abdomen vs. thigh & & $1.23[1.07-1.42]$ \\
\hline Abdomen vs. deltoid & & $0.97[0.84-1.12]$ \\
\hline \multicolumn{3}{|l|}{ Steady state } \\
\hline \multicolumn{3}{|l|}{$\mathrm{AUC}_{\mathrm{IDeg}, \tau, \mathrm{ss}}(\mathrm{pmol} \cdot \mathrm{h} / \mathrm{L})$} \\
\hline Thigh & 74,353 & \\
\hline Abdomen and deltoid & 80,087 & \\
\hline Abdomen and deltoid vs. thigh & & 1.08 [NA] \\
\hline \multicolumn{3}{|l|}{$C_{\text {max,IDeg,Ss }}(\mathrm{pmol} / \mathrm{L})$} \\
\hline Thigh & 3,367 & \\
\hline Abdomen and deltoid & 3,703 & \\
\hline Abdomen and deltoid vs. thigh & & $1.10[\mathrm{NA}]$ \\
\hline
\end{tabular}

Analyses based on 20 evaluations after injection in deltoid and abdomen, and 19 evaluations after injection in thigh. The steady-state simulation model assumes an individual clearance value for each subject regardless of injection region; thus, no variance estimates can reliably be calculated

$A U C_{I D e g, 0-120 h, S D}$ area under the insulin degludec serum concentration-time curve $0-120 \mathrm{~h}$ after a single dose, $A U C_{I D e g, \tau, S S}$ area under the insulin degludec serum concentration-time curve at steady state, $C I$ confidence interval, $C_{\text {max,IDeg,SD }}$ maximum insulin degludec serum concentration after a single dose, $C_{\max , \text { IDeg,SS }}$ maximum insulin degludec serum concentration at steady state, $N A$ not applicable

\subsection{Safety}

Most (six of nine) AEs were mild, and AEs were evenly distributed among the three SC dosing arms. No severe AEs or injection-site reactions were reported.

\section{Discussion}

The present study evaluated the pharmacokinetic and pharmacodynamic properties of IDeg following a single SC dose in the thigh, abdomen or deltoid region. A slightly higher total exposure of IDeg (by 6-7 \%) was observed following a single $\mathrm{SC}$ injection in the abdomen or deltoid region than in the thigh. No pronounced differences were observed in the glucose-lowering effect of IDeg between single-dose SC injection in the thigh, abdomen and deltoid regions. Simulated mean steady-state pharmacodynamic profiles supported a flat and stable glucose-lowering effect of IDeg across a 24-h dosing interval, and were within the same range for all three injection regions.

Several previous examples exist of the pharmacokinetic and pharmacodynamic properties of insulin products being affected by SC injection region. For example, some studies have reported slower insulin absorption and decreased glucose-lowering effects of short-acting insulins when injected SC in the thigh than in the abdomen [4-8] or deltoid $[4,5]$. The same finding has also been observed following administration of regular human insulin or neutral protamine Hagedorn (NPH) insulin in the thigh, compared with injection in the abdomen [7]. However, this is in contrast to data from a study comparing SC injection of $\mathrm{NPH}$ insulin in the abdomen or the thigh, which found no difference in measured pharmacokinetic parameters between the two regions [19]. A reason for this might be that the latter study (performed in only 11 people with type 1 diabetes) measured elimination rates from radiolabelled NPH insulin rather than pharmacokinetic parameters directly, and therefore might not have been appropriate to detect differences between injection regions.

With the advent of long-acting insulin products it is also important to determine whether any differences between injection regions are likely to occur with the use of these products. Existing data with radio-labelled insulin demonstrate that the absorption characteristics of insulin glargine are similar regardless of whether SC injection is conducted in the arm, abdomen or leg and no differences were seen in plasma exogenous insulin concentration or blood glucose levels between injection regions [20]. In contrast, with appropriate pharmacokinetic measurements, the AUC and maximum concentration of insulin detemir are reported to be higher (by approximately 10 and $20 \%$, respectively) following $\mathrm{SC}$ injection in the abdomen or deltoid than in the thigh [10]. The present study demonstrates a similar finding for IDeg.

When we tried to correlate this to the pharmacodynamics of IDeg, only small differences were seen in the glucose-lowering effect between the three injection regions following a single dose. Further, as IDeg reaches steady state at 2-3 days [21], multiple once-daily injections will contribute to the exposure and effect seen during a dosing interval at steady state, and it is supposed that the flat and consistent pharmacokinetic and pharmacodynamic profiles that are achieved at steady state would be less susceptible to minor differences in absorption rate. Indeed, the present 

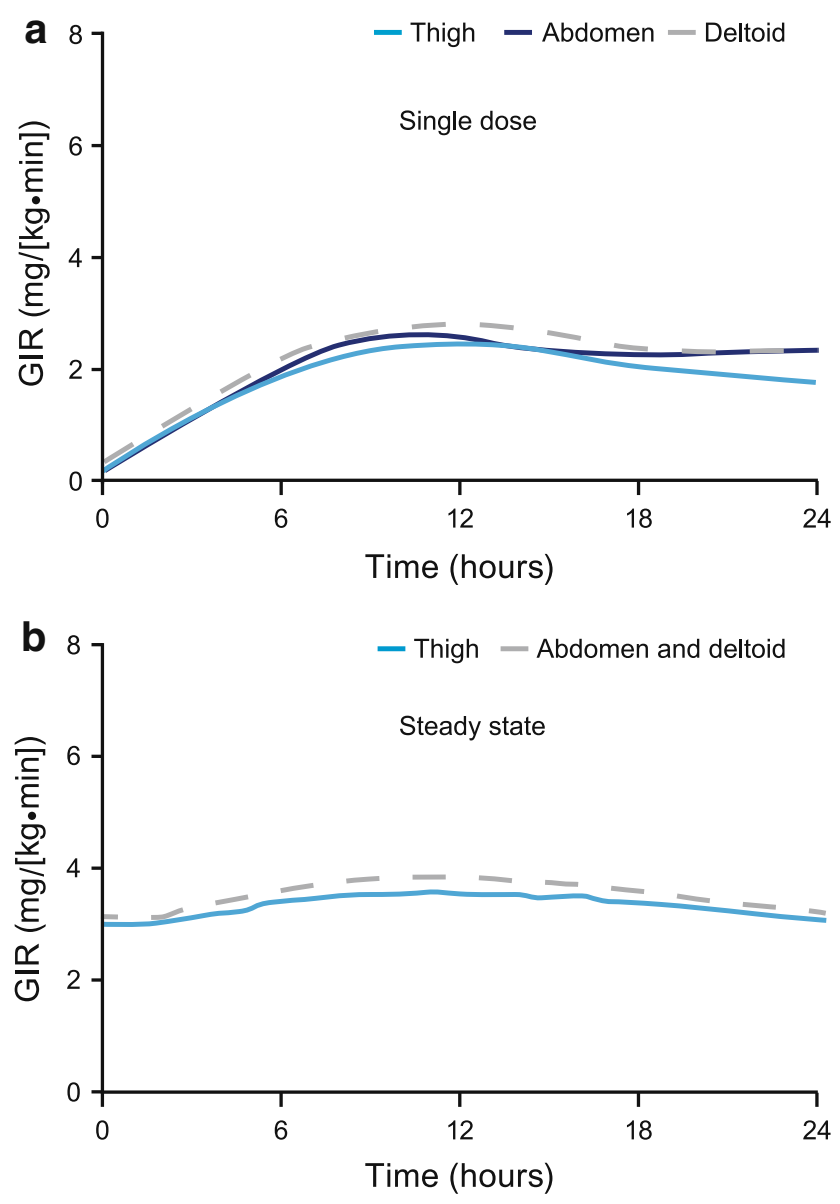

Fig. 2 a Mean 24-h pharmacodynamic profiles after a single subcutaneous dose of insulin degludec $(0.4 \mathrm{U} / \mathrm{kg})$, administered in the thigh, abdomen or deltoid. b Mean 24-h pharmacodynamic profiles when simulated to steady-state after once-daily subcutaneous administration of insulin degludec $(0.4 \mathrm{U} / \mathrm{kg})$ in the thigh, abdomen or deltoid. Because there was no difference in total exposure $\left(\mathrm{AUC}_{\text {IDeg,0-120h,SD }}\right)$ between the deltoid and abdomen after a single dose, the pharmacodynamic profiles for these two injection regions are superimposed in the steady-state simulation. $A U C_{I D e g, 0-120 h, S D}$ area under the insulin degludec serum concentration-time curve $0-120 \mathrm{~h}$ after a single dose, GIR glucose infusion rate

study supports this notion, since the inter-region differences in absorption rate observed after single-dose administration (as exemplified by $C_{\text {max,IDeg,SD }}$ ) diminish at steady state (evaluated by means of simulation) and thus are expected to have limited clinical relevance.

The present study was conducted in healthy, young adults (18-55 years), rather than patients with diabetes, in order to include a relatively homogenous cohort of subjects and thereby facilitate the detection of differences between injection regions, in accordance with regulatory standards $[22,23]$. With the inclusion of healthy subjects, a multipledose study with a clinically relevant dose would not have been acceptable, due to the risk of hypoglycaemia. Therefore, as discussed above, we extrapolated the pharmacokinetic and pharmacodynamic profiles of IDeg to steady state
Table 2 Glucose-lowering effect of insulin degludec following a single subcutaneous injection in the thigh, abdomen or deltoid and simulation-based once-daily steady-state values

\begin{tabular}{|c|c|c|}
\hline Pharmacodynamic endpoint & Mean estimate & $\mathrm{CV}$ \\
\hline \multicolumn{3}{|l|}{ Single dose } \\
\hline \multicolumn{3}{|l|}{$\mathrm{AUC}_{\mathrm{GIR}, 0-24 \mathrm{~h}, \mathrm{SD}}(\mathrm{mg} / \mathrm{kg})$} \\
\hline Thigh & 2,572 & 38 \\
\hline Abdomen & 2,833 & 42 \\
\hline Deltoid & 2,960 & 43 \\
\hline \multicolumn{3}{|l|}{$\mathrm{GIR}_{\max , \mathrm{SD}}[\mathrm{mg} /(\mathrm{kg} \cdot \min )]$} \\
\hline Thigh & 2.7 & 32 \\
\hline Abdomen & 3.0 & 37 \\
\hline Deltoid & 3.0 & 42 \\
\hline \multicolumn{3}{|l|}{ Steady state } \\
\hline \multicolumn{3}{|l|}{$\mathrm{AUC}_{\mathrm{GIR}, \tau, \mathrm{SS}}(\mathrm{mg} / \mathrm{kg})$} \\
\hline Thigh & 4,719 & \\
\hline Abdomen and deltoid & 5,005 & \\
\hline \multicolumn{3}{|l|}{$\mathrm{GIR}_{\max , \mathrm{SS}}[\mathrm{mg} /(\mathrm{kg} \cdot \min )]$} \\
\hline Thigh & 3.5 & \\
\hline Abdomen and deltoid & 3.8 & \\
\hline
\end{tabular}

Analyses based on 20 evaluations after injection in deltoid and abdomen, and 19 evaluations after injection in thigh. The steady-state simulation model assumes an individual clearance value for each subject regardless of injection region as well as individual parameters for each subject linking the insulin degludec concentration to GIR regardless of injection region; thus, no variance estimates can reliably be calculated

$A U C_{G I R, 0-24 h, S D}$ area under the GIR curve $0-24 \mathrm{~h}$ after a single dose, $A U C_{G I R, \tau, S S}$ area under the GIR curve at steady state, $C V$ coefficient of variation, GIR glucose infusion rate, GIR $\max _{\text {, SD }}$ maximum GIR after a single dose, $G I R_{\max , S S}$ maximum GIR at steady state

by means of simulation using a population pharmacokinetic/pharmacodynamic model based on data from the current trial. When including healthy subjects in a euglycaemic glucose clamp study it is important to address the potential confounding influence of endogenous insulin secretion during the glucose clamp. We did this by choosing a rather low clamp glucose target concentration of $4.5 \mathrm{mmol} / \mathrm{L}(81 \mathrm{mg} / \mathrm{dL})$, which was successful in suppressing the endogenous insulin secretion throughout the 24-h clamp, as assessed by serum C-peptide concentrations (additional data given in the Electronic Supplementary Material: Online Resource 1).

\section{Conclusion}

The results of the present study show that IDeg has a flat and stable glucose-lowering effect independent of injection region and that IDeg can be administered SC in the thigh, deltoid or abdomen with clinically comparable glucoselowering effects at steady state. 
Acknowledgments The involvement of the clinical site (Profil, Neuss; Germany) is gratefully acknowledged. Medical writing assistance was provided by apothecom scopemedical, UK, funded by Novo Nordisk. This study was funded by Novo Nordisk.

Contributions of authors Participated in research design: Nosek, Roepstorff, Thomsen, Haahr and Heise. Conducted experiments: Nosek, Coester, Thomsen, Kristensen and Heise. Performed data analysis: Roepstorff, Thomsen, Kristensen and Haahr. Wrote or contributed to the writing of the manuscript: Nosek, Coester, Roepstorff, Haahr and Heise.

Open Access This article is distributed under the terms of the Creative Commons Attribution Noncommercial License which permits any noncommercial use, distribution, and reproduction in any medium, provided the original author(s) and the source are credited.

\section{References}

1. Chowdhury TA, Escudier V. Poor glycaemic control caused by insulin induced lipohypertrophy. BMJ. 2003;327:383-4.

2. Peyrot M, Barnett AH, Meneghini LF, Schumm-Draeger PM. Factors associated with injection omission/non-adherence in the Global Attitudes of Patients and Physicians in Insulin Therapy study. Diabetes Obes Metab. 2012;14(12):1081-7. doi:10.1111/j. 1463-1326.2012.01636.x.

3. Minze MG, Dalal K, Irons BK. Removing barriers to insulin use. J Fam Pract. 2011;60:577-80.

4. Koivisto VA, Felig P. Alterations in insulin absorption and in blood glucose control associated with varying insulin injection sites in diabetic patients. Ann Intern Med. 1980;92:59-61.

5. Galloway JA, Spradlin CT, Nelson RL, Wentworth SM, Davidson JA, Swarner JL. Factors influencing the absorption, serum insulin concentration, and blood glucose responses after injections of regular insulin and various insulin mixtures. Diabetes Care. 1981;4:366-76.

6. Henriksen JE, Djurhuus MS, Vaag A, Thye-Ronn P, Knudsen D, Hother-Nielsen O, Beck-Nielsen H. Impact of injection sites for soluble insulin on glycaemic control in type 1 (insulin-dependent) diabetic patients treated with a multiple insulin injection regimen. Diabetologia. 1993;36:752-8.

7. Bantle JP, Neal L, Frankamp LM. Effects of the anatomical region used for insulin injections on glycemia in type I diabetes subjects. Diabetes Care. 1993;16:1592-7.

8. Süsstrunk H, Morell B, Ziegler WH, Froesch ER. Insulin absorption from the abdomen and the thigh in healthy subjects during rest and exercise: blood glucose, plasma insulin, growth hormone, adrenaline and noradrenaline levels. Diabetologia. 1982;22:171-4

9. Vora JP, Burch A, Peters JR, Owens DR. Relationship between absorption of radiolabeled soluble insulin, subcutaneous blood flow, and anthropometry. Diabetes Care. 1992;15:1484-93.
10. Morello CM. Pharmacokinetics and pharmacodynamics of insulin analogs in special populations with type 2 diabetes mellitus. Int $\mathrm{J}$ Gen Med. 2011;4:827-35.

11. Jonassen I, Havelund S, Hoeg-Jensen T, Steensgaard DB, Wahlund PO, Ribel U. Design of the novel protraction mechanism of insulin degludec, an ultra-long-acting basal insulin. Pharm Res. 2012;29:2104-14.

12. Owens DR. Insulin preparations with prolonged effect. Diabetes Technol Ther. 2011;13(suppl 1):S5-14.

13. Evans M, Schumm-Draeger PM, Vora J, King AB. A review of modern insulin analogue pharmacokinetic and pharmacodynamic profiles in type 2 diabetes: improvements and limitations. Diabetes Obes Metab. 2011;13:677-84.

14. Kuerzel GU, Shukla U, Scholtz HE, Pretorius SG, Wessels DH, Venter C, Potgieter MA, Lang AM, Koose T, Bernhardt E. Biotransformation of insulin glargine after subcutaneous injection in healthy subjects. Curr Med Res Opin. 2003;19:34-40.

15. Markussen J, Hougaard P, Ribel U, Sørensen AR, Sørensen E. Soluble, prolonged-acting insulin derivatives. I. Degree of protraction and crystallizability of insulins substituted in the termini of the B-chain. Protein Eng. 1987;1:205-13.

16. Kurtzhals P, Heise T, Strauss HM, Bøttcher SG, Granhall C, Haahr H, Jonassen I. Multi-hexamer formation is the underlying basis for the ultra-long glucose-lowering effect of insulin degludec. Diabetologia. 2011;54:S426.

17. Heise T, Hermanski L, Nosek L, Feldman A, Rasmussen S, Haahr H. Insulin degludec: four times lower pharmacodynamic variability than insulin glargine under steady-state conditions in type 1 diabetes. Diabetes Obes Metab. 2012;14:859-64.

18. Heise T, Hövelmann U, Nosek L, Bøttcher SG, Granhall C, Haahr H. Insulin degludec: twofold longer half-life and a more consistent pharmacokinetic profile than insulin glargine. Diabetologia. 2011;54:S425.

19. Henriksen JE, Vaag A, Hansen IR, Lauritzen M, Djurhuus MS, Beck-Nielsen H. Absorption of NPH (isophane) insulin in resting diabetic patients: evidence for subcutaneous injection in the thigh as the preferred site. Diabet Med. 1991;8:453-7.

20. Owens DR, Coates PA, Luzio SD, Tinbergen JP, Kurzhals R. Pharmacokinetics of 125I-labeled insulin glargine (HOE 901) in healthy men: comparison with NPH insulin and the influence of different subcutaneous injection sites. Diabetes Care. 2000;23:813-9.

21. Heise T, Nosek L, Bøttcher SG, Hastrup H, Haahr H. Ultra-longacting insulin degludec has a flat and stable glucose-lowering effect in type 2 diabetes. Diabetes Obes Metab. 2012;14:944-50.

22. Committee for Medicinal Products for Human Use. Guideline on the investigation of bioequivalence. European Medicines Agency. 2010. http://www.emea.europa.eu/docs/en_GB/document_library/ Scientific_guideline/2010/01/WC500070039.pdf. Accessed Apr 2014.

23. US Food and Drug Administration. Bioavailability and bioequivalence requirements. 21 CFR 21 Part 320. 2009. http:// www.accessdata.fda.gov/scripts/cdrh/cfdocs/cfcfr/cfrsearch.cfm? cfrpart=320. Accessed Apr 2014. 